\title{
Psoriasis treatment: traditional therapy
}

\author{
M Lebwohl, P T Ting, J Y M Koo
}

Ann Rheum Dis 2005;64(Suppl II):ii83-ii86. doi: 10.1136/ard.2004.030791

Even before the recent development of biological agents, a long list of effective treatments has been available for patients with psoriasis. Topical therapies such as corticosteroids, vitamin D analogues, and retinoids are used for localised disease. Phototherapy including broadband ultraviolet B (UVB), narrowband UVB, PUVA, and climatotherapy are effective for more extensive disease. Systemic therapies such as methotrexate, retinoids, and ciclosporin are effective for patients with refractory or extensive cutaneous disease.

$\mathrm{E}$ ven prior to the development of biologicals, the treatment of psoriasis was quite comprehensive, including numerous topical, systemic, and light therapies (table 1). ${ }^{12}$ Most of these continue to play a role in modern psoriasis therapy.

\section{TOPICAL THERAPY}

Most patients with psoriasis have skin lesions limited to localised areas such as the elbows or knees. For these patients, topical therapy may remain part of their therapeutic regimen whether or not they require additional treatments for psoriatic arthritis. Even those treated with phototherapy or systemic therapies, including biologicals, have residual lesions that may require topical remedies.

Topical corticosteroids remain the most widely prescribed medications for plaque psoriasis. These range in strength from weak, over-the-counter steroids such as $1 \%$ hydrocortisone to superpotent corticosteroids, such as clobetasol propionate, halobetasol propionate, betamethasone dipropionate in optimised base, and diflorasone diacetate in augmented base (table 2). The Stoughton-Cornell classification ranks the potency of topical corticosteroids on their ability to induce vasoconstriction. ${ }^{3}$ Topical corticosteroids are available in numerous vehicles including powders, sprays, lotions, solutions, creams, emollient creams, ointments, gels, and tape. Recently, clobetasol propionate and betamethasone valerate have both been introduced in foam vehicles that are cosmetically elegant and should improve compliance. Different vehicles are used on different body sites. For example, the scalp and other hair bearing areas are most easily treated with foams, solutions, and gels. Creams are most useful for daytime use, and ointments, which are often more effective but less appealing cosmetically, can be applied at night. Two possible exceptions are the newer foam vehicles, which have comparable clinical efficacy to ointments. $^{45}$

Side effects of topical corticosteroids, especially those that carry the superpotent categorisation, include cutaneous atrophy, development of striae, formation of telangiectasia, and a host of other local cutaneous effects such as the formation of an acneiform eruption known as perioral dermatitis on the face. ${ }^{67}$ Hypothalamic-pituitary-adrenal (HPA) axis suppression can occur with prolonged use of excessive quantities of topical corticosteroids, particularly if they are occluded or if superpotent corticosteroids are used continuously over large areas of the body. However, the cutaneous side effects are more commonly problematic than significant HPA axis suppression, which is seldom an issue. ${ }^{8}$

One of the most troubling features of topical corticosteroids is that patients develop tachyphylaxis, a phenomenon whereby medications that are highly effective initially, lose efficacy with prolonged use. To avoid tachyphylaxis and the other side effects of topical corticosteroids, regimens have been developed in which superpotent corticosteroids are applied twice daily for two weeks, after which they are applied on weekends only. Strong topical corticosteroids should also be avoided on the face and intertriginous sites, areas that are more prone to steroid side effects. The quantity of strong topical corticosteroids applied should be limited to 50 or 60 g per week, and occlusion should be avoided except on the scalp, palms, and soles. Strong corticosteroids should be avoided or used cautiously in children.

The second most commonly used group of medications consists of the vitamin D analogues. In the USA, calcipotriene is available in ointment, cream, and solution formulations. This agent is applied twice daily and is most often used in conjunction with topical corticosteroids. Its commonest side effect is irritation, primarily on the face and intertriginous sites. If large quantities of calcipotriene are applied, absorption of this vitamin $\mathrm{D}$ analogue can result in hypercalcaemia. ${ }^{9}$ Consequently, less than $120 \mathrm{~g}$ should be used weekly. Topical calcitriol is available in other parts of the world and may be less irritating on the face and in intertriginous sites. Other vitamin $\mathrm{D}$ analogues such as tacalcitol are also being used for psoriasis. Some vitamin D analogues are unstable, and

\begin{tabular}{ll}
\hline Table 1 & Psoriasis treatments before biologicals \\
\hline Topical therapy & Phototherapy \\
\hline Anthralin & UVB \\
Calcipotriene & Narrowband UVB \\
Calcitriol & PUVA \\
Corticosteroids & Bath-PUVA \\
Salicylic acid & Climatotherapy \\
Tars & Excimer laser \\
Tazarotene & \\
\hline Systemic therapy & Unconventional therapy \\
\hline Methotrexate & Antibiotics \\
Retinoids & Azathioprine \\
Ciclosporin & Oral calcitriol \\
& Colchicine \\
& FK-506 \\
& Topical 5-fluorouracil \\
& Fumaric acid esters \\
& Hydroxyurea \\
& Mycophenolate mofetil \\
& Propylthiouracil \\
& Sulfasalazine \\
& 6-Thioguanine \\
& Cryotherapy \\
& Radiation therapy \\
& \\
& \\
&
\end{tabular}




\begin{tabular}{|c|c|}
\hline Relative potency & Generic (brand) name \\
\hline Super high potency & $\begin{array}{l}\text { Clobetasol dipropionate } 0.05 \% \text { (Temovate) } \\
\text { (Olux foam) } \\
\text { Betamethasone dipropionate } 0.05 \% \text { (Diprolene) } \\
\text { Halobetasol propionate } 0.05 \% \text { (Ultravate) } \\
\text { Diflorasone diacetate } 0.05 \% \text { (Psorcon) }\end{array}$ \\
\hline High potency & $\begin{array}{l}\text { Fluocinonide } 0.05 \% \text { (Lidex) } \\
\text { Halcinonide } 0.05 \% \text { (Halog) } \\
\text { Amcinonide } 0.05-0.1 \% \text { (Cyclocort) } \\
\text { Desoximetasone } 0.25 \% \text { (Topicort) }\end{array}$ \\
\hline Mid potency & $\begin{array}{l}\text { Hydrocortisone valerate } 0.2 \% \text { (Westcort) } \\
\text { Triamcinolone acetonide } 0.1 \% \text { (Kenalog) } \\
\text { Betamethasone valerate } 0.1 \% \text { (Valisone) } \\
\text { (Luxiq foam) } \\
\text { Flurandrenolide } 0.05 \% \text { (Cordran) } \\
\text { Mometasone furoate } 0.1 \% \text { (Elocon) }\end{array}$ \\
\hline Low potency & $\begin{array}{l}\text { Hydrocortisone } 0.5-2.5 \% \text { (<1\% OTC; } \\
>1 \% \text { prescription) } \\
\text { Desonide } 0.05 \% \text { lotion, cream, ointment } \\
\text { (Desocort) } \\
\text { Dexamethasone } 0.1 \% \text { (Decadron) }\end{array}$ \\
\hline
\end{tabular}

consequently, they should only be combined with other medications that have been demonstrated not to affect their stability. ${ }^{10}$ Phototherapy may inactivate vitamin $\mathrm{D}$ analogues and, conversely, vitamin D analogues may block the therapeutic component of ultraviolet light; thus these topical agents should be applied after phototherapy, not before. ${ }^{11}$

Tazarotene gel, a recently developed topical retinoid for psoriasis, is available in $0.05 \%$ and $0.1 \%$ gels and creams. Topical retinoids may reverse some of the cutaneous atrophy caused by topical corticosteroids ${ }^{12}$ but are associated with local cutaneous irritation. Thus, they are often prescribed in combination with topical corticosteroids. ${ }^{13}$

Older topical remedies of psoriasis such as anthralin and coal tar are still in use. Because they are somewhat unpleasant to use, especially due to odour, product migration, and local irritation, they are less commonly prescribed than the aforementioned topical medications. Keratolytic preparations such as those containing salicylic acid and emollients are also effective for removing the excess scale that troubles many patients with psoriasis.

\section{LIGHT THERAPY}

Several forms of light therapy have been used to treat psoriasis for hundreds of years. In the 1920s, William Goeckerman combined the use of ultraviolet B (UVB) phototherapy with topical application of tars. ${ }^{14}$ This inpatient psoriasis regimen, known as the Goeckerman regimen, is still occasionally used, but outpatient regimens using UVB phototherapy with emollients have largely replaced the inpatient regimens.

Broadband UVB phototherapy has also been in use since the 1920s. It has not been associated with the development of skin cancers despite the concomitant application of tars, which are considered carcinogenic. ${ }^{15}$ This therapy remains one of the safest treatments for cutaneous psoriasis, but requires treatments at least three times per week for several months to be effective.

The most effective wavelengths of UVB light used for the treatment of psoriasis fall in a very narrow range, 311$313 \mathrm{~nm} .{ }^{16}{ }^{17}$ This has led to the development of narrowband UVB phototherapy, which is more efficient than broadband phototherapy. ${ }^{16}$ In the few years that narrowband UVB phototherapy has been used, no increase in cutaneous malignancies has been reported. More experience will be needed to firmly establish the safety of narrowband UVB phototherapy. The excimer laser is a powerful beam of $308 \mathrm{~nm}$ light (another form of narrowband ultraviolet light) that has been used successfully to treat localised plaques of psoriasis including those on the palms and soles. ${ }^{18}$

In the 1970s, a powerful new treatment of psoriasis known as PUVA was introduced. PUVA involves the ingestion or topical application of a photosensitising medication, usually 8-methoxypsoralen. Patients are then exposed to UVA, which activates the 8-methoxypsoralen. Once activated, this drug crosslinks DNA strands preventing replication of keratinocytes and induces death of activated T cells in skin. ${ }^{19}$ Bath PUVA, a topical photosensitising method, involves immersion of either localised areas (such as the hands or feet) or the whole body in water containing dissolved 8-methoxypsoralen capsules prior to UVA exposure. The topical use of this agent is not associated with adverse systemic symptoms such as nausea. Psoriasis clears in most patients treated with PUVA. PUVA may also benefit psoriatic arthritis in some patients. ${ }^{20}$ For optimal effect, patients are typically treated two to three times per week for several months. PUVA is significantly more effective than broadband UVB, but it is associated with the development of squamous cell carcinomas of the skin. The risk of non-melanoma cutaneous malignancies increases with the number of treatments but are rare in dark skinned patients. $^{21}$ Most recently, there have been unconfirmed reports of an increased risk of malignant melanomas that correlates with the number of treatments and time of follow up, the increased risk being noted 15 years after starting PUVA. $^{22}$

Climatotherapy, the oldest form of phototherapy involving exposure to sunlight, is well established at a number of clinics around the world. Perhaps the most successful is the psoriasis treatment centre at the Dead Sea. ${ }^{23}$ At $300 \mathrm{~m}$ below sea level, the Dead Sea is the lowest point on earth. Its mineral content is greater than that of any other naturally occurring body of water on earth. The extra $300 \mathrm{~m}$ through which sunlight has to pass, combined with the mineral haze over the Dead Sea, results in light exposure that has proved highly beneficial for psoriasis. Results are comparable with those obtained with broadband UVB phototherapy. ${ }^{24}$

\section{SYSTEMIC THERAPY}

The three approved systemic treatments for psoriasis are: methotrexate, acitretin, and ciclosporin. Their use, advantages, and disadvantages, are discussed below.

\section{Methotrexate}

Methotrexate, the oldest systemic therapy for psoriasis, remains one of the most effective treatments for psoriasis and psoriatic arthritis. It has a number of short term side effects including bone marrow toxicity, nausea, aphthous stomatitis, and development of megaloblastic anaemia. Even when properly prescribed, bone marrow toxicity of methotrexate is responsible for several deaths each year. ${ }^{25}$ Caution must be used in administering other medications to patients on methotrexate because certain drugs result in higher methotrexate levels. Specifically, co-trimoxazole (trimethoprim/sulfamethoxazole) results in increased methotrexate toxicity by several mechanisms. ${ }^{26}$ Decreases in renal function lower methotrexate clearance thereby increasing toxicity, and thus methotrexate needs to be used with increased caution in the elderly. ${ }^{27}$ Certain non-steroidal anti-inflammatory drugs also interfere with methotrexate secretion. ${ }^{26}$ Nausea and megaloblastic anaemia of methotrexate can be avoided by concomitant prescription of folic acid ( $1-5 \mathrm{mg}$ daily) 
although this may interfere with the efficacy of methotrexate. $^{28}$

Chronic administration of methotrexate has been associated with the development of hepatic fibrosis. For a number of reasons documented in the literature, the frequency of hepatic fibrosis appears to be increased in patients with psoriasis compared to patients with rheumatoid arthritis. Consequently, guidelines call for periodic liver biopsies to monitor patients with psoriasis treated long term with methotrexate. Liver biopsies are recommended after $1.5 \mathrm{~g}$ cumulative methotrexate dose and approximately every $1.5 \mathrm{~g}$ thereafter if liver function tests are normal. ${ }^{29}$

Methotrexate is prescribed in doses up to $30 \mathrm{mg}$ per week for cutaneous psoriasis. Typically, a test dose of $2.5-7.5 \mathrm{mg}$ is given one day in week one; if well tolerated, patients are titrated to $15 \mathrm{mg}$ of methotrexate/week, given on one day per week. The dose is adjusted in accordance with the clinical response and side effects.

\section{Acitretin}

Oral retinoids were introduced for the treatment of psoriasis over the past two decades. Etretinate was the first retinoid available for psoriasis, but because of its long half-life, it could not be prescribed for women of childbearing potential due to the risk of long term teratogenicity. Acitretin, the active metabolite of etretinate, has a shorter half-life. Once it was approved, etretinate was withdrawn from the market. Acitretin is also associated with teratogenicity, but because of its shorter half-life, it can be given to women as long as they are not planning a pregnancy for three years after discontinuing its use. In the presence of alcohol, however, acitretin is converted back to etretinate, so caution must be used in women of childbearing potential to make sure they do not consume alcohol when taking acitretin. ${ }^{30}$

Both acitretin and etretinate are associated with numerous mucocutaneous side effects. At doses of $1 \mathrm{mg} / \mathrm{kg}$ daily, many patients develop hair loss. Cheilitis, characterised by fissuring and cracking of the lips, is common as are several other cutaneous side effects. A sticky sensation to the skin, desquamation of the palms and soles, thinning of the nail plates, and development of pyogenic granulomas in paronychial areas can occur. Elevation of cholesterol levels, and especially triglycerides, is common even at lower doses of etretinate or acitretin. Triglycerides can become so elevated that pancreatitis can occur. Muscle aches and pains are also common. Elevation of liver function tests occurs in a small proportion of patients and must be monitored.

Acitretin is prescribed in doses of 10-50 mg daily. At doses of $10-25 \mathrm{mg}$ in combination with UVB or PUVA phototherapy, acitretin is highly effective in clearing the condition in most patients with minimal side effects. ${ }^{31}$ Higher doses are associated with more adverse reactions but limited improvement in psoriasis. With chronic use, acitretin can be associated with the development of calcification of ligaments and tendons. Although these developments are usually asymptomatic, pain near ligaments and tendons in patients on acitretin warrants radiological examination to determine if the drug should be discontinued. Retinoids can benefit psoriatic arthritis in some patients. ${ }^{32}$

\section{Ciclosporin}

Ciclosporin, the most effective oral therapy for psoriasis, was fortuitously discovered to help psoriasis when it was administered to transplant patients with the disease. The side effects of ciclosporin are numerous and include hypertension, nephrotoxicity, hypomagnesaemia, hyperkalaemia, hyperuricaemia, elevation of liver function tests, development of paraesthesias, and hypertrichosis. In transplant patients, this immunosuppressive drug is associated with an increase in infections and lymphoproliferative diseases. If given for extended periods of time, nephrotoxicity occurs in most patients; hence, guidelines for the treatment of psoriasis with ciclosporin in the USA have suggested that it should not be administered for more than one year. ${ }^{33}$ All of the safety and efficacy data on the use of ciclosporin for psoriasis are based on doses up to $5 \mathrm{mg} / \mathrm{kg}$ daily, but the US Food and Drug Administration lists $4 \mathrm{mg} / \mathrm{kg}$ daily in the package insert. Nevertheless, it is usual to use higher doses for more severely affected patients.

Numerous additional drugs have been used off-label for psoriasis. Hydroxyurea, azathioprine, sulfasalazine, oral FK506, and 6-thioguanine have all been used effectively to treat psoriasis when other treatments have failed. With the advent of biological agents, many of the systemic therapies currently used for psoriasis will continue to be prescribed in combination therapy or as monotherapy depending on the particular circumstances of each patient.

\section{Authors' affiliations \\ M Lebwohl, The Mount Sinai School of Medicine, New York, NY, USA P T Ting, J Y M Koo, University of California at San Francisco, San Francisco, CA, USA}

Competing interests: $\operatorname{Dr} M$ Lebwohl or members of his faculty have been investigators for: Abbott Laboratories, Allergan, Amgen/Wyeth, Biogen, Centocor, Connetics, Fujisawa, Galderma, Genentech, GlaxoSmithKline, and Novartis. In addition, Dr Lebwohl has been a consultant and/or speaker for: Allergan, Amgen/Wyeth, Biogen, Connetics, and Fujisawa. Dr Koo has been a consultant for Allergan, Amgen/Wyeth, Biogen, Connetics, Fujisawa, Genentech, and Novartis.

Correspondence to: $M$ Lebwohl, 5 East 98th Street, New York, NY 10029-6574, USA; lebwohl@aol.com

\section{REFERENCES}

1 Lebwohl M, Ali S. Treatment of psoriasis. Part 1. Topical therapy and phototherapy. J Am Acad Dermatol $2001 ; 45: 487-98$.

2 Lebwohl M, Ali S. Treatment of psoriasis. Part 2. Systemic therapies. J Am Acad Dermatol 2001;45:649-61.

3 Cornell RC, Stoughton RB. Correlation of the vasoconstriction assay and clinical activity in psoriasis. Arch Dermatol 1985;121:63-7.

4 Feldman SR, Sangha N, Setaluri V. Topical corticosteroid in foam vehicle offers comparable coverage compared with traditional vehicles. J Am Acad Dermatol 2000;42:1017-20.

5 Andreassi L, Giannetti A, Milani M. Efficacy of betamethasone valerate mousse in comparison with standard therapies on scalp psoriasis: an open, multicentre, randomized, uncontrolled, cross-over study on 241 patients. Br J Dermatol 2003;148:134-8.

6 Pierard GE, Pierard-Franchimont C, Ben Mosbah T, Arrese Estrada J. Adverse effects of topical corticosteroids. Acta Derm Venereol Suppl (Stockh) 1989;151:26-30; discussion 47-52.

7 Goa KL. Clinical pharmacology and pharmacokinetic properties of topically applied corticosteroids. A review. Drugs 1988;36(suppl):551-61.

8 Ellison JA, Patel L, Ray DW, David TJ, Clayton PE. Hypothalamic-pituitaryadrenal function and glucocorticoid sensitivity in atopic dermatitis. Pediatrics 2000; 105(4 Pt 1):794-9.

9 Scott LJ, Dunn CJ, Goa KL. Calcipotriol ointment. A review of its use in the management of psoriasis. Am J Clin Dermatol 2001;2:95-120.

10 Patel B, Siskin S, Krazmien R, Lebwohl M. Compatibility of calcipotriene with other topical medications. J Am Acad Dermatol 1998;38:1010-1.

11 Lebwohl M, Quiiije J, Gilliard J, Rollin T, Watts O. Topical calcitriol is degraded by ultraviolet light. J Invest Dermatol 2003;121:594-5.

12 Kaidbey K, Kopper SC, Sefton J, Gibson JR. A pilot study to determine the effect of tazarotene gel $0.1 \%$ on steroid-induced epidermal atrophy. Int J Dermatol 2001;40:468-71.

13 Bruner CR, Feldman SR, Ventrapragada M, Fleischer AB Jr. A systematic review of adverse effects associated with topical treatments for psoriasis. Dermatol Online J 2003;9:2.

14 Perry HO, Soderstrom CW, Schulze RW. The Goeckerman treatment for psoriasis. Arch Dermatol 1968;98:178-82.

15 Pittelkow MR, Perry HO, Muller SA, Maughan WZ, O'Brien PC. Skin cancer in patients with psoriasis treated with coal tar. A 25 -year follow-up study. Arch Dermatol 1981;117:465-8.

16 Coven TR, Burack LH, Gilleaudeau R, Keogh M, Ozawa M, Krueger JG. Narrowband UV-B produces superior clinical and histopathological resolution of moderate-to-severe psoriasis in patients compared with broadband UV-B. Arch Dermatol 1997;133:1514-22. 
17 Gupta G, Long J, Tillman DM. The efficacy of narrowband ultraviolet B phototherapy in psoriasis using objective and subjective outcome measures. Br J Dermatol 1999;140:887-90.

18 Trehan M, Taylor CR. Medium-dose 308-nm excimer laser for the treatment of psoriasis. J Am Acad Dermatol 2002;47:701-8.

19 Coven TR, Walters IB, Cardinale I, Krueger JG. PUVA-induced lymphocyte apoptosis: mechanism of action in psoriasis. Photodermatol Photoimmunol Photomed 1999; 15:22-7.

20 Gorham H. Treatment of psoriatic arthropathy by PUVA. Physiotherapy 1980;66:40.

21 Stern RS, Liebman EJ, Vakeva L. Oral psoralen and ultraviolet-A light (PUVA) treatment of psoriasis and persistent risk of nonmelanoma skin cancer. PUVA Follow-up Study. J Natl Cancer Inst 1998;90:1278-84.

22 Stern RS, Nichols KT, Vakeva LH. Malignant melanoma in patients treated for psoriasis with methoxsalen (psoralen) and ultraviolet $A$ radiation (PUVA). The PUVA Follow-Up Study. N Engl J Med 1997;336:1041-5.

23 Abels DJ, Rose T, Bearman JE. Treatment of psoriasis at a Dead Sea dermatology clinic. Int J Dermatol 1995;34:134-7.

24 Schiffner R, Schiffner-Rohe J, Wolfl G, Landthaler M, Glassl A, Walther T, et al. Evaluation of a multicentre study of synchronous application of narrowband ultraviolet B phototherapy (TL-01) and bathing in Dead Sea salt solution for psoriasis vulgaris. Br J Dermatol 2000;142:740-7.

25 Gutierrez-Urena S, Molina JF, Garcia CO, Cuellar ML, Espinoza LR. Pancytopenia secondary to methotrexate therapy in rheumatoid arthritis. Arthritis Rheum 1996;39:72-6.
26 Furst DE. Practical clinical pharmacology and drug interactions of low-dose methotrexate therapy in rheumatoid arthritis. $\mathrm{Br} J$ Rheumatol 1995;34(suppl):220-5.

27 Haagsma CJ. Clinically important drug interactions with disease-modifying antirheumatic drugs. Drugs Aging 1998;13:281-9.

28 van Ede AE, Laan RF, Rood MJ, Huizinga TW, van de Laar MA, van Denderen $C J$, et al. Effect of folic or folinic acid supplementation on the toxicity and efficacy of methotrexate in rheumatoid arthritis: a forty-eight week, multicenter, randomized, double-blind, placebo-controlled study. Arthritis Rheum 2001;44:1515-24.

29 Roenigk HH Jr, Auerbach R, Maibach H, Weinstein G, Lebwohl M. Methotrexate in psoriasis: consensus conference. J Am Acad Dermatol 1998;38:478-85.

30 Larsen FG, Jakobsen P, Knudsen J, Weismann K, Kragballe K, NielsenKudsk F. Conversion of acitretin to etretinate in psoriatic patients is influenced by ethanol. J Invest Dermatol 1993;100:623-7.

31 Lebwohl M, Drake L, Menter A, Koo J, Gottlieb AB, Zanolli M, et al. Consensus conference: acitretin in combination with UVB or PUVA in the treatment of psoriasis. J Am Acad Dermatol 2001;45:544-53.

32 Klinkhoff AV, Gertner E, Chalmers A, Gladman DD, Stewart WD, Schachter GD, et al. Pilot study of etretinate in psoriatic arthritis. J Rheumatol 1989;16:789-91.

33 Lebwohl M, Ellis C, Gottlieb A, Koo J, Krueger G, Linden K, et al. Cyclosporine consensus conference: with emphasis on the treatment of psoriasis. J Am Acad Dermatol 1998;39:464-75. 